\title{
Book Review: Dispute Resolution and E-Discovery
}

Milton Luoma

Follow this and additional works at: https://commons.erau.edu/jdfsl

Part of the Computer Engineering Commons, Computer Law Commons, Electrical and Computer Engineering Commons, Forensic Science and Technology Commons, and the Information Security Commons

\section{Recommended Citation}

Luoma, Milton (2012) "Book Review: Dispute Resolution and E-Discovery," Journal of Digital Forensics, Security and Law. Vol. 7 : No. 3 , Article 6. DOI: https://doi.org/10.15394/jdfsl.2012.1130 Available at: https://commons.erau.edu/jdfsl/vol7/iss3/6

This Article is brought to you for free and open access by

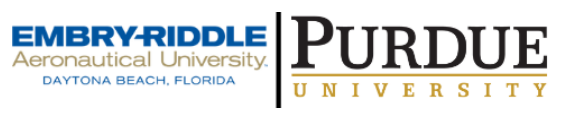
the Journals at Scholarly Commons. It has been accepted for inclusion in Journal of Digital Forensics, Security and Law by an authorized administrator of Scholarly Commons. For more information, please contact commons@erau.edu.

(c)ADFSL 


\title{
BOOK REVIEWS
}

\author{
Jigang Liu \\ Editor \\ Metropolitan State University \\ St. Paul, MN 55106 \\ Jigang.Liu@metrostate.edu
}

If you have any suggestions on books for review, or you would like to write a book review for us, or you have any comments and concerns on the book reviews published on this column, please feel free to send an email to Jigang Liu at Jigang.Liu@metrostate.edu.

\section{BOOK REVIEW}

Garrie, D.B., \& Griver, Y.M., Eds. (2012). Dispute Resolution and e-Discovery. Thomson Reuters Westlaw, 570 pages, ISBN-13: 9780314604484, US\$149.00.

Reviewed by Milton Luoma, JD, (Milt.Luoma@metrostate.edu)

As is apparent from its title, this book tackles two very current and difficult legal issues - electronic discovery and dispute resolution. The authors tie the two legal concepts together in an effort to provide litigants and practitioners a less expensive and less time consuming alternative than is typically the case with traditional litigation and court proceedings. By including electronic discovery in the discussions, the authors recognize the importance and significance of electronic discovery in mediation and arbitration as it is in traditional litigation.

The book consists of 11 chapters, each written by a different author who is an expert in the area of the particular chapter. In addition, there are 45 appendices that include all of the outside sources a professional would need - everything from arbitration protocols, sample court orders, to the electronic rules for the London Court of International Arbitration.

The book is easy to read and comprehend, but it is written for the professionals who work in the area of electronic discovery, attorneys, forensic experts, as well as mediators and arbitrators. The book begins with a discussion and definition of electronic discovery followed by an explanation of Federal Rules of Civil Procedure, and finally, dispute resolution options. The chapters give tips and suggestions for the professional throughout the book.

In civil litigation a party and his or her attorneys are required to come to meetand-confer proceedings prepared and ready to provide and request electronically stored information (ESI). The reality of these meet-and-confer sessions is that attorneys are often confused or unprepared. As a Craig Ball, an attorney and 
forensic consultant, has stated that meet-and-confer sessions involve "two lawyers who don't trust each other negotiating matters neither understands."

This book tackles the most difficult issues that arise in electronic discovery, including costs and the burdens of e-discovery, key word searches, and proportionality. The book then discusses the two most popular forms of dispute resolution - mediation and arbitration. The authors discuss the benefits and issues involved in both mediation and arbitration and compare the two. The authors conclude that many e-discovery problems can be avoided through dispute resolution. With the complexity and costs associated with e-discovery, the alternatives of mediation or arbitration are much more appealing.

In mediation, the goal of the mediator, or third-party neutral, is to resolve the case or issue on terms all parties can accept. The authors point out that to settle issues in e-discovery, the mediator must be able to address issues that are not directly related to the merits of the case. The author gives the example that in pursuing a claim in a lawsuit the cost of pursuing the claim or the risk or losing at trial may play a part in the decisions of litigation. A party may decide to drop all or a portion of the case for reasons other than the merits of the case. Daniel Gelb, one of the authors of this book, wrote "... mediation is a productive means to determine whether e-discovery should function as a quantifiable in reaching settlement or whether it is collateral to the dispute and risks of being improperly leveraged to drive up costs." This chapter by Gelb has a list of 25 issues that can be addressed in mediation. They range from what experts should be retained to the method and type of electronically stored information to be provided.

Gelb further points out that mediation demands creative use of technology to cut costs and time. Lack of understanding of the e-discovery process is one of the stumbling blocks to the process and that mediation can help that process. In addition, Gelb suggests tools to review in determining whether mediation would help litigants in the e-discovery area.

This book has numerous tips for the practitioner, including suggestions for keyword searches and agreement in mediation. The author tells the mediator and parties once they have agreed upon the keywords to use that the parties should use sampling to see if these keywords are adequate and do not produce too little or too much information before finalizing the agreement.

Then, as another suggestion, the book explores the use of arbitration in ediscovery. In arbitration the parties choose a neutral fact finder. Unlike mediation where the parties must come to an agreement, in arbitration the arbitrator listens to the testimony, evidence and arguments of the parties, and reviews their arguments and information, and then makes the final decision. The parties can agree that the arbitration is either binding or nonbinding in nature. If the parties decide the arbitrator's decision is nonbinding then they can bring motions to the court to reargue their e-discovery issues. The chapters on arbitration discuss strategies litigants can use in difficult areas in e-discovery, 
such as preservation, proportionality, cost allocation, search terms and privilege. One suggestion is that the parties can agree or one party can convince the arbitrator to limit certain areas of e-discovery.

The book also discusses the use of a Special Master, the process of selecting Special Masters and final reports. In the chapter concerning the use of the Special Master, the author discusses several case studies. One case study shows how the Special Master may be appointed to determine whether parties have complied with court orders to provide ESI. The book also discussed the potential minefields and dispute resolution strategies for the practitioner. They include forms of ESI production, key word searches, scope and proportionality in ediscovery, and cost allocation. The author of this section, Maura Grossman, has given the reader some key take-away points to help in these difficult areas.

This book thoroughly covers all the relevant topics and choices in this area of ediscovery and alternate dispute resolution. Most of the major cases in this area are listed mainly in the footnotes. The book also contains a glossary and index.

The only criticism this reviewer has is that more case studies showing the success of the methodology in mediation and arbitration would help illustrate the authors' points. Further, it would be helpful if the authors had done a cost analysis comparing and contrasting the use of alternate dispute resolution in lieu of court litigation. However, throughout the book the authors give tips to the professional, make key points and give helpful suggestions while providing alternate actions for litigants. Electronic discovery is an area in which litigants can be sanctioned for provided too much information, too little information, or providing information in the wrong format. This book is a helpful resource for the professional to guide them to methods that may save time, money, and stress. 
Journal of Digital Forensics, Security and Law, Vol. 7(3) 